\title{
Geomonumentos de Caçapava do Sul (Centro-Sul do RS, Brasil) e seu Destaque na Paisagem: A Quantificação do Valor Estético do Geopatrimônio e Suas Aplicações
}

\section{Geosites of Caçapava do Sul (south-central RS State, Brazil) and their Landscape Ddifference: The Quantitative Assessment of the Aesthetic Value of Geoheritage and its Applications}

\section{Resumo:}

O presente trabalho avalia, através da percepção de 37 estudantes de geoconservação em nível de pós-graduação, o parâmetro "destaque na paisagem” para os principais geomonumentos do município de Caçapava do Sul (extremo sul do Brasil). Os respondentes atribuíram notas de 1 a 10 para cada cena apresentada, sendo que algumas cenas representavam um mesmo geossítio, de ângulos diferentes. As cenas mais valorizadas pelo público especialista foram aquelas em que as elevações são mais altas, mais íngremes e irregulares, com rocha exposta e vegetação nativa, e onde várias geoformas compõem um conjunto harmônico. As Pedras das Guaritas e a Pedra da Cruz, vistas de diferentes pontos da estrada RS-625, tiveram as cenas melhor avaliadas de todo o estudo, com notas acima de 9, constituindo as prioridades para implantação de miradores para interpretação da paisagem. Propõem-se, também, os melhores pontos de interpretação e contemplação da paisagem para as diferentes geoformas da Serra do Segredo e do Cerro da Angélica. Tais avaliações podem constituir a base para futuras medidas de gestão, valorização e divulgação do geopatrimônio e do patrimônio paisagístico de Caçapava do Sul.

\begin{abstract}
:
This paper focuses on the assessment of the parameter "landscape difference" for important geosites of Caçapava do Sul (southernmost Brazil) through the measured perception of graduate geoconservation students. The evaluators have assigned grades between 1 and 10 to each presented scene. Some scenes represent the same geosite, viewed from different angles and viewpoints. The most valuable scenes, according to the specialized evaluators, were those in which the hills are higher, steeper, and more irregular, with exposed rock outcrops and indigenous vegetation, and those where two or more hills form a harmonious group. The geosites Guaritas and Pedra da Cruz, viewed form different viewpoints on the road RS-625, have had the most valuable scenes, with final medium grades above 9 . These are the immediate priorities for the setting of landscape interpretation facilities. This research also resulted in the proposition of the best viewpoints for the observation and interpretation of the areas of the Segredo and Angélica hills. Such assessment can consist in the first step of future initiatives of management, appreciation, and divulgation of geological and landscape heritage of the Caçapava do Sul municipality.
\end{abstract}

André W. de Borba *

\section{* Universidade Federal de Santa Maria, Programa de Pós-graduação em Geografia (PPGGEO/UFSM), Grupo de Pesquisa em Patrimônio Natural, Geoconservação e Gestão da Água (PANGEA).}

Palavras-chave:

Geossítios,

Valor estético,

Quantificação,

Paisagem,

Caçapava do Sul/RS

Key-Words:

Geosites,

Aesthetic value, Quantification, Landscape, Caçapava do Sul/RS 


\section{INTRODUÇÃO E CONTEXTO DA PES-} QUISA geoconservação constitui uma tendência re-
cente nas geociências (HENRIQUES et al., 2011), utilizando uma série de conceitos e ferramentas que buscam uma integração do conhecimento geológico e geomorfológico com a proteção do meio ambiente e com o desenvolvimento humano e socioeconômico de áreas rurais pedregosas. Os fundamentos dessa nova área do conhecimento são os conceitos de geodiversidade e geopatrimônio (ou patrimônio geológico). A geodiversidade pode ser entendida como a variedade natural dos materiais, feições e processos que conformam a natureza abiótica, incluindo suas relações e interpretações (GRAY, 2004; BRILHA, 2005). Esse conceito, nascido como uma contração de "diversidade geológica e geomorfológica", vincula-se à ideia de que a natureza é a união indissociável de geodiversidade e biodiversidade, e que ambas devem ser valorizadas e protegidas. Os valores atribuídos à geodiversidade são: (a) intrínseco ou de existência; (b) estético, vinculado à beleza cênica; (c) cultural, relacionado à influência da natureza abiótica sobre costumes, materiais, toponímia ou atividades tradicionais; (d) funcional, que diz respeito às funções do substrato para o ser humano, bem como para os ecossistemas e organismos vivos; (e) científico e educativo; e (f) econômico, vinculado à tradicional abordagem da geodiversidade como fonte de recursos minerais (e.g. BRILHA, 2005). A partir dessa noção dos valores da geodiversidade e da contraposição com a necessidade de consumo de seus recursos como gerador de bem-estar à humanidade, desenvolveu-se a ideia de geopatrimônio, entendido como o conjunto dos elementos mais representativos (geossítios ou geomonumentos) da geodiversidade de um determinado território naqueles valores não relacionados a seu consumo/destruição.

A definição do geopatrimônio de um território e o estabelecimento de prioridades de proteção, gestão e uso desses recursos passam necessariamente pela realização de inventários e avaliações quali-quantitativas, com diversas metodologias (BRILHA, 2005; PENA-DOS-REIS \& HENRIQUES, 2009; LIMA et al., 2010; PEREIRA, 2010; FASSOULAS et al., 2012; BRILHA, 2016). As avaliações quantitativas baseiam-se na atribuição de notas para diferentes características dos geomonumentos, em geral vinculadas a seus distintos valores e potencialidades. Uma das metodologias mais interessantes, adaptada a áreas pedregosas, pouco povoadas e de perfil rural, é aquela desenvolvida por Fassoulas et al. (2012) para regiões montanhosas do interior da ilha de Creta, na Grécia. De acordo com aquela metodologia, os geomonumentos podem ser avaliados por meio de critérios: (a) geocientíficos, como geodiversidade intrínseca, raridade e representatividade; (b) ecológicos, sobretudo vinculados à importância do geomonumento para a estruturação de habitat; (c) culturais, como o uso dos geossítios em obras de arte ou sua importância histórica; (d) estéticos, nomeadamente a visibilidade e o destaque na paisagem; (e) econômicos, como o número de visitantes; e (f) de uso potencial, como a acessibilidade, a fragilidade e a intensidade de uso.

O presente trabalho focaliza exatamente um dos critérios propostos por Fassoulas et al. (2012) para avaliar o valor estético de um geomonumento: o critério "landscape difference", que pode ser traduzido como "destaque na paisagem". Esse critério consiste, especificamente, nas diferenças de forma, textura e coloração entre o geomonumento (um cerro, um afloramento, etc.) e seu entorno, ou seja, a paisagem circundante. Um geomonumento desprovido de destaque em relação ao seu entorno recebe a nota 1, e uma elevação com o máximo destaque frente à paisagem circundante receberia a nota 10. Para se obter o escore estético de um elemento do geopatrimônio, o referido critério é integrado (através de média simples) ao parâmetro "visibilidade", que consiste no número de pontos, separados por mais de $1 \mathrm{~km}$, a partir dos quais é possível visualizar o geomonumento considerado (FASSOULAS et al., 2012).

O município de Caçapava do Sul, reconhecido por lei como "capital gaúcha da geodiversidade" (RIO GRANDE DO SUL, 2015), possui em seus limites territoriais uma série de geomonumentos de substancial destaque na paisagem. No trabalho de Borba et al. (2013), as Pedras das Guaritas, a Pedra do Segredo e o Cerro da Angélica, entre outros, receberam as mais altas notas para o destaque na paisagem. Entretanto, naquela pesquisa, cada geossítio recebeu uma única nota para sua visibilidade e outra para seu destaque na paisagem, considerando-se o geossítio como um todo, e não contemplando cenas, visadas ou ângulos em particular. Aqui, o objetivo é o de verificar, através da percepção de profissionais envolvidos com as geociências e a geoconservação, os valores absoluto e relativo do critério destaque na paisagem de cenas ou visadas específicas, algumas delas do mesmo geomonumento mas obtidas de locais e ângulos diferentes. Esta abordagem permite, em primeiro lugar, compreender a maneira pela qual os profissionais percebem e valoram o geopatrimônio caçapavano 
em seu potencial estético/cênico. Além disso, em termos de gestão, esta abordagem tem o potencial de auxiliar futuramente na definição dos melhores pontos, seja em rodovias, estradas ou terrenos públicos e privados, para a implantação de miradores (mirantes, belvederes) e para a adoção de estratégias de interpretação da paisagem e do geopatrimônio.

\section{MATERIAIS E MÉTODOS}

A percepção da natureza pelo ser humano, de acordo com Soulé (1997), baseia-se em três dimensões: (1) a experiencial, relacionada às sensações de alegria ou tristeza, identificação ou repulsa; (2) a valorativa, relacionada a julgamentos e classificações; e (3) a científica-analítica, que busca a organização e explicação dos fenômenos naturais. Originadas em porções diferentes do cérebro, todas influenciam ao mesmo tempo a percepção que as pessoas constroem sobre o ambiente e suas características visuais. Portanto, sempre haverá subjetividade nesse tipo de abordagem (MARTÍNEZ-VEGA et al., 2003). Ainda assim, estudos de percepção ambiental, através do julgamento estético de simulações fotográficas, podem fornecer uma medida adequada da qualidade da paisagem (e.g. ARIAZA et al., 2004). Zube et al. (1987) apontam que, nas áreas da gestão, planejamento e arquitetura, o uso de simulações fotográficas para apreensão de preferências, mediante a apresentação de imagens coloridas e realistas, é bastante difundido. Por esse motivo, optou-se neste trabalho por utilizar esse tipo de abordagem. Evidentemente, é importante frisar que a percepção apenas visual, a partir de fotografias, para avaliar o potencial de miradores e outros equipamentos de interpretação, tem suas limitações. Somente a apreciação in loco poderia complementar o panorama com sons, odores e sensações relacionadas à temperatura e à umidade do ar, além de agregar os aspectos relacionados à profundidade e à perspectiva em três dimensões.

Os sujeitos selecionados como respondentes para o presente trabalho foram 37 estudantes em nível de mestrado e doutorado que cursaram a disciplina "Geopatrimônio e geoconservação" nos programas de pós-graduação em geografia e em geociências, respectivamente da UFSM (Santa Maria) e da UFRGS (Porto Alegre), entre os anos de 2013 e 2016. Esta amostragem é, ao mesmo tempo, intencional e acidental, pois mesmo que só tenham sido consultados estudantes que estivessem cursando a disciplina, não havia qualquer controle do pesquisador sobre as matrículas desses sujeitos no curso. Uma amostra intencional, neste caso, justifica-se pelo fato de que os profissionais e pesquisadores responsáveis por inventários e avaliações quantitativas do geopatrimônio serão exatamente os egressos desse tipo de curso/ disciplina, com a qualificação técnica prévia em geologia, geomorfologia, ecologia e outros aspectos da paisagem. Esse fato situa a presente investigação, dentre os diferentes modelos de percepção da paisagem de Zube et al. (1982), naquele paradigma chamado de "especialista".

Para a realização das avaliações por parte dos sujeitos, foram utilizadas 32 fotografias de diversas elevações situadas na chamada 'metade sul' gaúcha, nos municípios de Caçapava do Sul, Bagé, Santana da Boa Vista, São Gabriel, Rosário do Sul e São Vicente do Sul. As fotografias foram obtidas a partir de pontos selecionados como potenciais miradores. Para Fuertes-Gutiérrez \& Fernández-Martínez (2010), os miradores (viewpoints) são geossítios compostos, integrando um ponto de observação e, à distância, elementos de destaque visual/paisagístico. Todos os cerros selecionados, mesmo com diferentes substratos, morfologias e origens, possuem algum destaque em relação à paisagem circundante. As fotografias (Fig. 1), coloridas e em alta resolução, mas sem qualquer outro tratamento digital, foram apenas recortadas de maneira uniforme, para que todas tivessem uma proporção de aproximadamente $25 \mathrm{~cm}$ de largura por $10 \mathrm{~cm}$ de altura, e distribuídas em uma apresentação do software PowerPoint ${ }^{\circledR}$, sendo uma fotografia por slide, com fundo de cor negra com o número correspondente à fotografia em fonte branca.

Cada respondente recebeu uma planilha com números de 1 a 32 e foi instado a registrar, ao lado de cada número, uma nota de 1 a 10 para o valor do parâmetro "destaque na paisagem" para cada uma das imagens. As únicas informações providas pelo pesquisador aos sujeitos foram (a) o conceito de "destaque na paisagem" (landscape difference) para Fassoulas et al. (2012) e (b) o critério utilizado por aqueles autores para a atribuição de notas, desde 1 (sem destaque na paisagem) até 10 (grande destaque na paisagem). Nenhum outro detalhe sobre os cerros, nem mesmo seus nomes ou localizações, foram informados aos respondentes até o final da avaliação. A apresentação com as 32 fotografias foi exibida três vezes em cada evento de realização do teste, para que os respondentes se acostumassem ao conjunto de imagens, 
atribuíssem as notas e, por fim, confirmassem sua avaliação individual para cada cena/visada. Ao final, os sujeitos foram convidados a registrarem livremente, no verso do instrumento de pesquisa, os atributos que os tinham levado a atribuir notas maiores ou menores às imagens daquele conjunto. Para o presente trabalho, foram selecionadas apenas as 18 cenas que retratam geomonumentos localizados dentro dos limites municipais de Caçapava do Sul (Fig. 1).

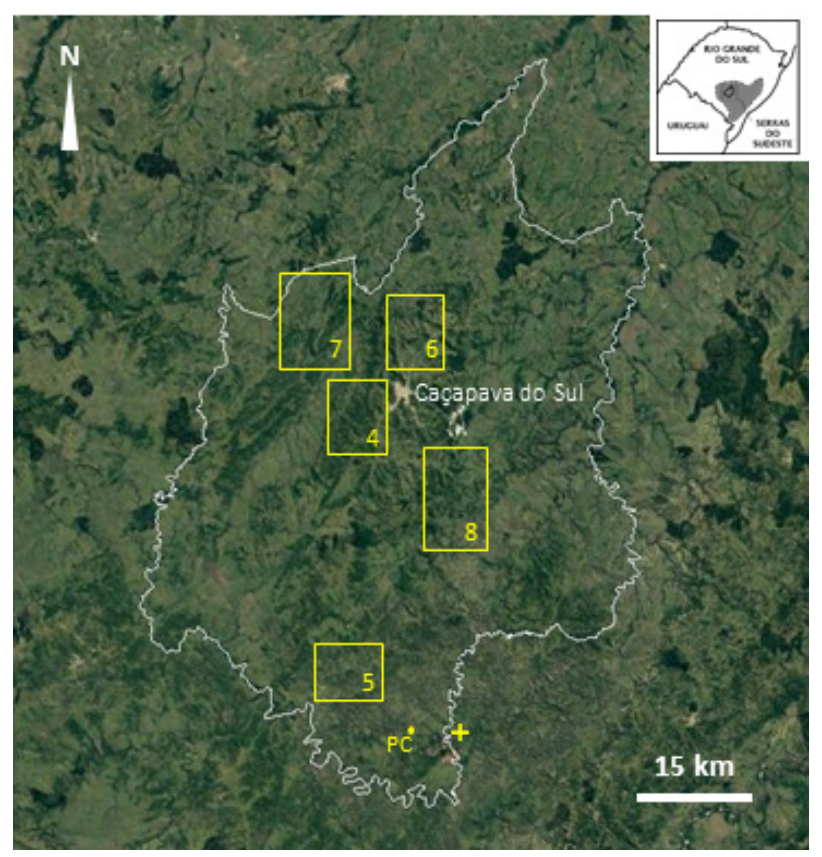

Figura 1: Contorno dos limites municipais de Caçapava do Sul, sobre imagem obtida no GoogleEarth ${ }^{\circledR}$ (meramente ilustrativa). Os retângulos amarelos indicam a posição dos recortes espaciais de outras figuras citadas no texto (figuras 4, 5, 6, 7 e 8). O ponto PC indica o local de observação (potencial mirador) para o conjunto da Pedra da Cruz, cujas geoformas situam-se, na verdade, no município vizinho de Santana da Boa Vista (no local marcado pela cruz amarela). No canto superior direito, a posição de Caçapava do Sul na província geomorfológica das Serras do Sudeste, centro-sul do Estado do Rio Grande do Sul. Fonte: :Elaborado pelo autor

\section{RESULTADOS E DISCUSSÃO}

\subsection{Aspectos gerais e destaques da avaliação}

As notas atribuídas para cada fotografia por cada um dos 37 respondentes foram registradas em planilha do Microsoft Excel ${ }^{\circledR}$, e são apresentadas na Tabela I. A partir dessas notas, foram calculados a média e o desvio-padrão para cada uma das cenas analisadas, por meio das ferramentas disponibilizadas pelo referido software. As cenas (Fig. 2) que obtiveram as notas médias mais altas e os menores desvios-padrão localizam-se na região sul do município de Caçapava do Sul: (1) a vista clássica do geomonumento das Pedras das
Guaritas (Fig. 2A), de oeste para leste, a partir do ponto de coordenadas 30049'26'S e 53o30'52'W, na rodovia estadual RS-625 (não pavimentada), que recebeu nota média de 9,36 com desvio-padrão de 0,83 ; e (2) a vista do conjunto de quatro cerros da Pedra da Cruz (Fig. 2B), também para leste, a partir do ponto de coordenadas 30052'47'’S e 53o28'20''W às margens da RS-625, que obteve 9,35 de média, com desvio-padrão de 0,87 (Tab. I). No outro extremo, as cenas que obtiveram as menores notas, dentre as elevações do município, foram: (3) uma das vistas do Cerro do Perau (Fig. 2C), de leste para oeste, com nota final de 5,80 e desvio de 2,03; e (4) uma vista do Cerro dos Nascimentos (Fig. 2D), a partir da estrada que liga o Cerrito do Ouro ao Passo da Promessa, com nota média de 5,23 e desvio de 2,17.

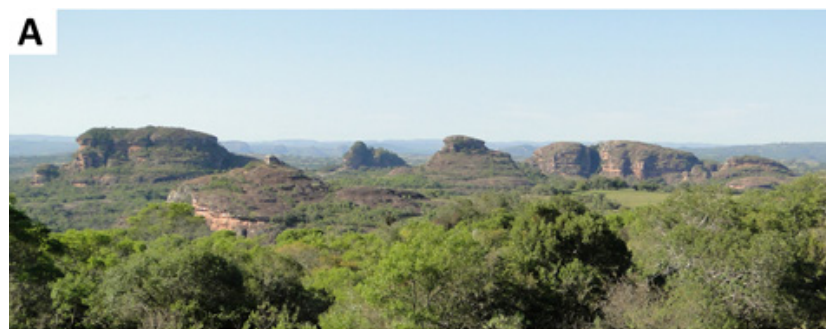

B
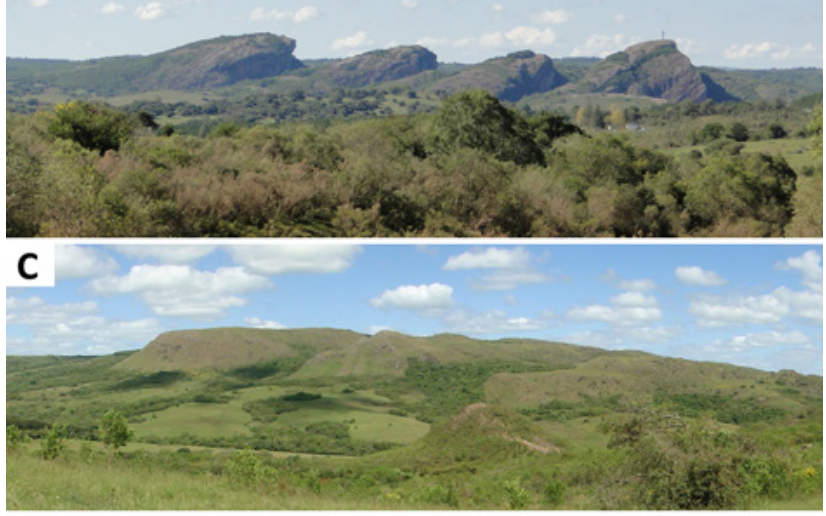

D

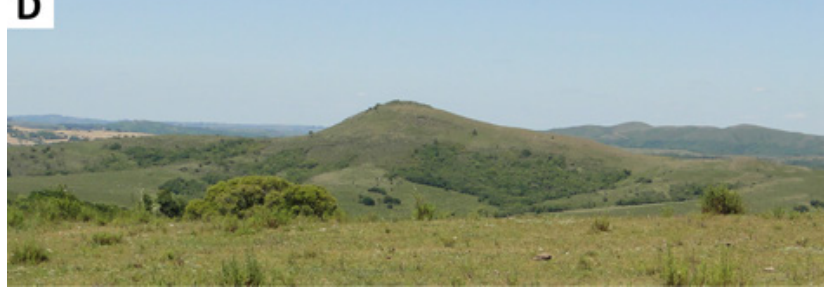

Figura 2: Cenas que receberam as mais altas e mais baixas notas finais pelos avaliadores, neste estudo: (A) a vista clássica das Pedras das Guaritas, com média final 9,36; (B) o conjunto da Pedra da Cruz, com 9,35; (C) uma vista do Cerro do Perau, com 5,80; e (D) a cena que representa do Cerro dos Nascimentos, com 5,23, sendo a elevação de menor destaque na paisagem de todo o estudo..

Fonte: Acervo do autor

As ideias expressas livremente pelos respondentes 
como seus "critérios de avaliação" do destaque na paisagem estão representadas no gráfico da Figura 3. Ideias relacionadas a irregularidades na forma/morfologia das elevações foram citadas por 17 respondentes, mesmo número de citações aos contrastes entre diferentes cores ou tonalidades entre os cerros e o entorno.
Efetivamente, se forem consideradas as fotografias avaliadas neste estudo, verifica-se que as cenas de maior nota final são aquelas em que os geomonumentos: (a) são mais altos e mais íngremes; (b) apresentam formas/morfologias mais irregulares; (c) combinam-se produzindo conjuntos harmônicos; (d) possuem exposição de rocha; e (e) apresentam vegetação nativa preservada.

Tabela I - Notas atribuídas para cada cena por todos os sujeitos respondentes deste estudo, com notas finais médias (média simples) e desvio-padrão; as cenas estão agrupadas por geomonumento ou contexto geopatrimonial a que se vinculam.

\begin{tabular}{|c|c|c|c|c|c|c|c|c|c|c|c|c|c|c|c|c|c|c|}
\hline \multirow{2}{*}{$\frac{\text { Ares/ conterto }}{\cos s}$} & \multicolumn{6}{|c|}{ Serra do segredo } & \multicolumn{4}{|c|}{ Dedras das Guritas } & \multicolumn{3}{|c|}{ Cerro da Angelica } & \multicolumn{2}{|c|}{ Cerro do Persu (granios) } & \multicolumn{3}{|c|}{ Cerros de riolitoos/ignimberitos } \\
\hline & $\begin{array}{l}\text { Pedra do } \\
\text { Abelha }\end{array}$ & $\begin{array}{l}\text { Pedra do } \\
\text { Segredo }\end{array}$ & $\begin{array}{c}\text { Pedra do } \\
\text { Indio }\end{array}$ & $\begin{array}{l}\text { Pedra do } \\
\text { Segredo } / / \mathrm{S}\end{array}$ & $\begin{array}{l}\text { Pedra do } \\
\text { Sezredo o/ N }\end{array}$ & $\begin{array}{c}\text { Pedra do } \\
\text { Segredo desde } \\
\text { P. Leào }\end{array}$ & $\begin{array}{l}\text { Geoforma } \\
\text { isclats } \\
\text { arrectondada }\end{array}$ & $\begin{array}{l}\text { Geoforma } \\
\text { isoladac/ } \\
\text { fratura }\end{array}$ & $\begin{array}{l}\text { Vista classica, } \\
\text { conjumto de } \\
\text { cerros } p / E\end{array}$ & $\begin{array}{c}\text { Pedra da } \\
\text { Cruz }\end{array}$ & \begin{tabular}{|c|c|} 
BR.153 \\
visode o/N
\end{tabular} & $\begin{array}{c}\text { Sta. Antonio } \\
\mathrm{p} / \mathrm{t}\end{array}$ & $\begin{array}{c}\text { Pedreira } \\
\text { B8-392 p/ } \\
5\end{array}$ & Visada $\mathrm{p} / \mathrm{N}$ & Visade p/o & $\begin{array}{c}\text { Cerro dos } \\
\text { Nascimentos }\end{array}$ & $\begin{array}{l}\text { Cerro dos } \\
\text { Machiodos }\end{array}$ & $\begin{array}{c}\text { Cerro do } \\
\text { Buscio }\end{array}$ \\
\hline Sujeto/ Figura & $F_{i 8} 45$ & Fip $4 \mathrm{~B}$ & Fig 46 & Fie 40 & File $\Delta \mathrm{C}$ & Fig. $4 \mathrm{E}$ & $\mathrm{Fl}_{\mathrm{ZSC}} \mathrm{SC}$ & Fig. 5B & $\mathrm{Fiz}_{2 \mathrm{~A}}$ & Fig. 28 & $\mathrm{Fig} 80$ & $\mathrm{Fe} 88$ & $\mathrm{Fil} B \mathrm{C}$ & Fig. 68 & $\mathrm{Fil} 2 \mathrm{C}$ & $\mathrm{FQ}, 20$ & Fip.78 & Fib $x$ \\
\hline 1 & 9 & 9 & 9 & 9.5 & 8.5 & 10 & 8.5 & 9.5 & 10 & 10 & 9 & 7.5 & 7,5 & 7.5 & 7 & , & 7.5 & 8.5 \\
\hline 2 & 9 & 10 & 10 & 10 & 10 & 10 & 10 & ${ }_{10}^{10}$ & 10 & ${ }_{10} 0$ & 20 & 8 & 7 & 9 & 9 & 8 & 8 & 9 \\
\hline 3 & ? & 8 & 6 & 6 & 8 & 8 & 8 & 8 & 9 & 8 & 10 & 9 & 8 & ? & 6 & 6 & 6 & 9 \\
\hline 4 & 10 & 10 & $\therefore$ & 10 & 10 & 2 & 10 & 10 & 10 & 10 & 9 & ? & 8 & 8 & 6 & 6 & 7 & 10 \\
\hline${ }_{6}^{5}$ & 6 & 8.5 & 6.5 & 4 & 5 & 5 & ? & 7 & 7 & 7.5 & 2.5 & 2 & 2 & 4 & 2 & 2 & 3 & 6 \\
\hline 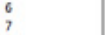 & ${ }_{8}^{10}$ & 10 & 9 & $?$ & 2 & 9 & 10 & 10 & 10 & 10 & 8 & 7 & 6 & 7 & 3 & 4 & $?$ & 8 \\
\hline 8 & $\begin{array}{l}8 \\
6.5\end{array}$ & $\begin{array}{c}8 \\
65\end{array}$ & $?$ & $\frac{7}{7}$ & $?_{7}^{7}$ & ${ }_{8}^{8}$ & $\begin{array}{l}8 \\
6\end{array}$ & 7,5 & $\begin{array}{l}8.5 \\
8\end{array}$ & $\begin{array}{l}8.5 \\
75\end{array}$ & ${ }_{5}^{8}$ & $\begin{array}{l}7.5 \\
3.5\end{array}$ & 25 & $\begin{array}{c}7.5 \\
3\end{array}$ & 25 & $\frac{7}{2}$ & 3 & 8 \\
\hline 9 & 10 & 10 & 7,5 & 8 & 8,5 & 8,5 & 9,5 & o, & 9,5 & 10 & 8 & 8,5 & 6 & 7.5 & 6 & s.5. & is & 77 \\
\hline 10 & 10 & 7 & 3 & 7 & 6 & 6 & 4 & 6 & 8 & 10 & 5 & 5 & 2 & 3 & 5 & 3 & 3 & 9.5 \\
\hline 11 & 8 & 9 & 8 & 8 & 9 & 8 & 8 & 8 & 9 & 8 & 8 & 9 & ; & 8 & 8 & 5 & 6 & $?$ \\
\hline 12 & 9 & 10 & 9 & 8 & 8 & 8 & 9 & 8 & 9 & 9 & 9 & 7 & , & 7 & 7 & 6 & 6 & 9 \\
\hline 13 & 9 & 9 & 8 & 8 & 8,5 & 7 & 7 & 9 & 9,5 & 9 & 8,5 & 5 & 6 & 6 & 4 & 4 & 3 & 73 \\
\hline 14 & 10 & 10 & 8 & 10 & 10 & ? & 8 & 10 & 8 & 8 & 7 & 3 & 3 & 3 & 2 & 1 & 3.5 & 7 \\
\hline is & 8 & 9 & 8 & 7 & 7 & 6 & 9 & 9 & 9 & 8 & 6 & 4 & 4 & s & 5 & 4 & s & 7 \\
\hline 16 & $\therefore$ & 10 & 9 & 9 & 10 & 10 & 9 & 10 & 10 & 10 & 8 & 7 & 6 & 8 & 6 & 6 & 8 & 10 \\
\hline $\begin{array}{l}17 \\
18\end{array}$ & 8,5 & 10 & 9 & 9 & 10 & 9 & 9 & 10 & 10 & 10 & 8 & 8 & 8 & 9 & 8 & 6 & 7 & 9 \\
\hline $\begin{array}{l}18 \\
19 \\
19\end{array}$ & ${ }^{10}$ & 8 & ${ }_{70}^{10}$ & 8,5 & ${ }_{8}^{10}$ & 10 & 8 & 10 & 10 & 10 & 10 & 10 & 9 & 9 & 8 & 8 & $?$ & 10 \\
\hline 20 & 6 & $\begin{array}{l}8 \\
9\end{array}$ & 7 & $\begin{array}{l}7 \\
4\end{array}$ & $\begin{array}{l}8 \\
8\end{array}$ & 9 & $\begin{array}{l}8 \\
5\end{array}$ & 8 & 9 & $\begin{array}{l}10 \\
10\end{array}$ & 8 & 7 & 6 & 8 & ${ }_{2}^{7}$ & 5 & 3 & 8 \\
\hline 21 & 8 & 9 & 5 & 6 & 6 & 8 & 8 & 6 & 8 & 9 & 5 & 4 & 4 & 5 & 4 & 3 & $\begin{array}{l}4 \\
4\end{array}$ & ${ }_{5}^{4}$ \\
\hline 22 & 8 & 9 & 9 & 8 & 10 & 10 & 9 & 10 & 9 & 9 & 8 & ; & 7 & 8 & 8 & 7 & 7 & 8 \\
\hline 23 & ; & 9 & 9 & 8 & 9 & 10 & 8 & 10 & 10 & 10 & 9 & 8 & ; & 8 & 7 & ; & ; & 10 \\
\hline 24 & 10 & 10 & 9 & 9 & 10 & 10 & 8 & 10 & 10 & 10 & 10 & ; & 7 & 8 & 7 & 7 & 10 & 8 \\
\hline 25 & 10 & 9 & 9 & 8 & 10 & 9 & 9 & 10 & 10 & 10 & 7 & 7 & 7 & 8 & 7 & 7 & 8 & 9 \\
\hline 26 & 5 & 5 & 5 & 5 & 6 & 6 & 5 & 5 & 8 & 8 & 3 & 3 & 3 & 3 & 3 & 3 & 3 & 7 \\
\hline 27 & ${ }_{8}^{10}$ & 8 & 10 & 7 & 7 & 10 & 8 & 10 & 10 & ${ }^{10}$ & 10 & ${ }_{10}^{10}$ & 7 & 7 & 10 & 5 & 5 & 10 \\
\hline $\begin{array}{l}28 \\
29\end{array}$ & 8 & $?$ & 8 & 7 & 8 & 8 & 8 & 9 & 9 & 9 & 8 & 7 & 7 & 7 & 6 & 7 & 8 & 8 \\
\hline${ }_{30}^{29}$ & $?$ & 8 & 78 & 10 & 10 & 10 & ? & 10 & $\begin{array}{l}10 \\
10\end{array}$ & $\begin{array}{l}10 \\
10\end{array}$ & 10 & ${ }_{10}^{6}$ & 8 & ${ }_{8}^{10}$ & 6 & 9 & $?$ & $\begin{array}{l}10 \\
10\end{array}$ \\
\hline $\begin{array}{l}30 \\
31\end{array}$ & ${ }_{10}^{9}$ & $\begin{array}{l}10 \\
10\end{array}$ & $\begin{array}{l}10 \\
10\end{array}$ & ${ }_{10}^{9}$ & $\begin{array}{l}10 \\
10\end{array}$ & ${ }_{10}^{9}$ & $\begin{array}{l}10 \\
10\end{array}$ & $\begin{array}{l}10 \\
10 \\
10\end{array}$ & $\begin{array}{l}10 \\
10\end{array}$ & $\begin{array}{l}10 \\
10\end{array}$ & $\begin{array}{l}9 \\
8\end{array}$ & $\begin{array}{l}10 \\
7\end{array}$ & 7 & $\begin{array}{l}8 \\
8\end{array}$ & $?$ & ${ }_{10}^{7}$ & io & $\begin{array}{l}10 \\
10\end{array}$ \\
\hline $\begin{array}{l}31 \\
32 \\
32\end{array}$ & 9 & $\begin{array}{l}10 \\
6\end{array}$ & $\begin{array}{l}100 \\
7\end{array}$ & $\begin{array}{l}10 \\
10\end{array}$ & $\begin{array}{l}100 \\
8\end{array}$ & $\begin{array}{c}10 \\
8\end{array}$ & $\begin{array}{c}10 \\
9\end{array}$ & $\begin{array}{l}10 \\
6 \\
6\end{array}$ & $\begin{array}{l}10 \\
10\end{array}$ & $\begin{array}{l}10 \\
9 \\
9\end{array}$ & $\begin{array}{l}8 \\
6\end{array}$ & $\begin{array}{l}7 \\
5\end{array}$ & $\begin{array}{l}7 \\
6\end{array}$ & 7 & 6 & $\begin{array}{l}10 \\
6\end{array}$ & $\begin{array}{l}100 \\
9\end{array}$ & $\begin{array}{c}10 \\
9\end{array}$ \\
\hline 33 & 10 & ? & ? & 9 & 10 & 9 & 10 & 10 & 10 & 10 & 9 & 8 & 8 & 3 & 5 & 5 & 6 & $?$ \\
\hline 34 & 10 & 10 & 7.5 & 7.5 & 10 & 7.5 & 10 & 10 & 10 & 10 & 8 & 7.5 & 7.5 & is & 5 & 5 & 5 & 10 \\
\hline 35 & 10 & 10 & 10 & 8 & $?$ & 8 & 8 & $?$ & 10 & 10 & 8 & 1 & 1 & 8 & 2 & 3 & 1 & 10 \\
\hline 36 & 7.5 & 10 & 7.5 & 7.5 & 7.5 & 7 & 7.5 & 10 & 10 & 8.5 & 9 & 8 & 5 & 5 & 5 & 2.5 & 25 & 8 \\
\hline 37 & 7.5 & 10 & 10 & 7,5 & 10 & 10 & 10 & 3 & 10 & 10 & 7,3 & 3 & 5 & 3 & 3 & 2,5 & 2,3 & 10 \\
\hline Medis & 8,62 & 8,95 & 8,08 & 7,91 & 8.59 & 8,38 & 8,28 & 8,74 & 9,36 & 9,35 & 7,88 & 6,61 & 5,96 & 6,78 & 5,800 & 5,23 & 5,82 & 8,49 \\
\hline Desvio-gudito & 1.37 & 1.24 & 1.62 & 1.57 & 1.46 & 1.48 & 1.50 & 1.61 & 0.83 & 0.87 & 1.88 & 2.25 & 1.98 & 1.87 & 203 & 2.17 & 2.42 & 1.48 \\
\hline
\end{tabular}

Houve 15 citações a termos relacionados à altura ou dimensão aparente das elevações, mas apenas 3 pessoas referiram-se à declividade ou a ângulos de inclinação das formas. A presença de rocha exposta foi citada explicitamente por 10 pessoas, e igual número de respondentes manifestaram ter valorizado mais a presença de vegetação nativa. Houve 4 menções aos aspectos de "amplitude da bacia visual", "extensão abrangida" ou "distância". Termos mais genéricos, como "destaque", "imponência", "expressividade", "beleza" ou "valor estético" foram muito citados (17 citações no total), mas não permitem a compreensão de quais fatores específicos levaram a tais manifestações, confundindo-se com o próprio conceito de destaque na paisagem. Ainda foram citadas as ideias de "composição" ou "formação de conjunto harmônico" (2 citações), "presença do elemento humano" (2 vezes), "ausência do elemento humano" (1 citação), e até mesmo "sensação de segurança" e "sensação de tranquilidade" (1 citação de cada).
Além de ilustrar bem os critérios que o público especializado utiliza para construir mentalmente uma valoração das elevações, permite traçar uma prioridade de gestão: de uma forma geral, ao se pensar em uma estratégia de (geo)turismo e interpretação geopatrimonial para Caçapava do Sul, deve-se ter como primeiros alvos de intervenção os pontos de maior nota deste estudo, nomeadamente as Pedras das Guaritas e o conjunto de cerros da Pedra da Cruz. Isso reforça também a importância da rodovia RS-625 (a "estrada velha da mina") para a valorização interna e externa do município e de toda a região do Alto Camaquã, bem como a relevância da manutenção da qualidade ambiental e visual dessas áreas frente a empreendimentos como mineração e silvicultura.

\section{2 Áreas da Serra do Segredo e das Pedras das Gua- ritas}

Além dos aspectos mais gerais dos resultados apresentados na Tabela I, salienta-se aqui o alto valor das 
avaliações de destaque na paisagem de todas as cenas da área da Serra do Segredo (Fig. 4).

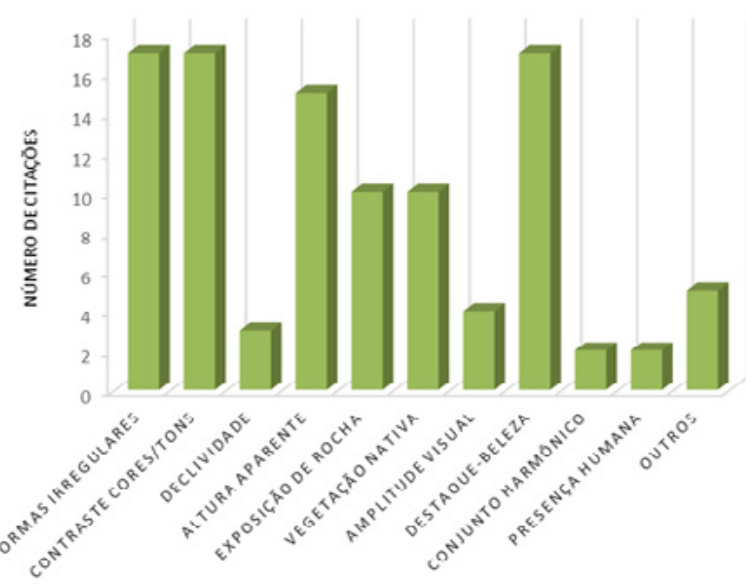

Figura 3: Gráfico de ideias manifestadas livremente pelos respondentes como seus critérios pessoais para atribuição de notas de destaque na paisagem (no eixo das abscissas) versus a frequência dessas citações (no eixo das ordenadas) ao longo dos quatro anos de aplicação do instrumento.

Fonte: Elaboração do autor

Nestas, as notas finais distribuem-se entre 7,91 e 8,95, e da área das Pedras das Guaritas (Fig. 5), cujas notas finais variam de 7,96 a 9,36, em ambas sempre com o desvio-padrão abaixo de 1,62, ou seja, com uma substancial consistência nas avaliações. Além de serem geomonumentos de singular importância para a estruturação de habitat (BORBA et al., 2016), seu destaque na paisagem, sua qualidade visual e seu consequente potencial (geo) turístico as tornam áreas altamente relevantes para a geoconservação e proteção da natureza em geral, bem como para seu uso sustentável em busca do desenvolvimento local.

Na Serra do Segredo (Fig. 4A), cuja paisagem é dominada por elevações arredondadas de conglomerados e arenitos expostos, com florestas higrófilas de encosta, seis cenas de três geoformas diferentes foram avaliadas: (1) quatro visadas diferentes da Pedra do Segredo (Fig. 4B, 4C, 4D, 4E), geomonumento de maior apelo turístico, por já possuir um "parque municipal", com estacionamento e infraestrutura mínima de recepção de visitantes; (2) uma visada de sul para norte da Pedra da Abelha (Fig. 4F), geoforma isolada e com muita rocha exposta; e (3) uma visada, também para norte, da Pedra do Índio, geoforma cortada por fraturas e cercada de florestas, cujas paredes da face sul são recobertas de musgos, líquens e bromélias, sem muita rocha exposta (Fig. 4G). Para a Pedra do Segredo, a nota final mais alta $(8,95)$ foi obti- da pela cena em que a geoforma está sendo iluminada diretamente pelo sol do final da tarde, o que reforça o contraste entre suas cores cinza e rosada e a cor verde da vegetação florestal circundante, dando a sensação de maior "isolamento" da geoforma. Isso demonstra também a importância da direção da incidência do sol para o planejamento de trilhas e/ou de miradores para programas (geo)turísticos. Destacam-se também notas altas para a visada mais tradicional da Pedra do Segredo $(8,59)$, para norte, a partir do acesso ao parque, e para a Pedra da Abelha $(8,62)$.
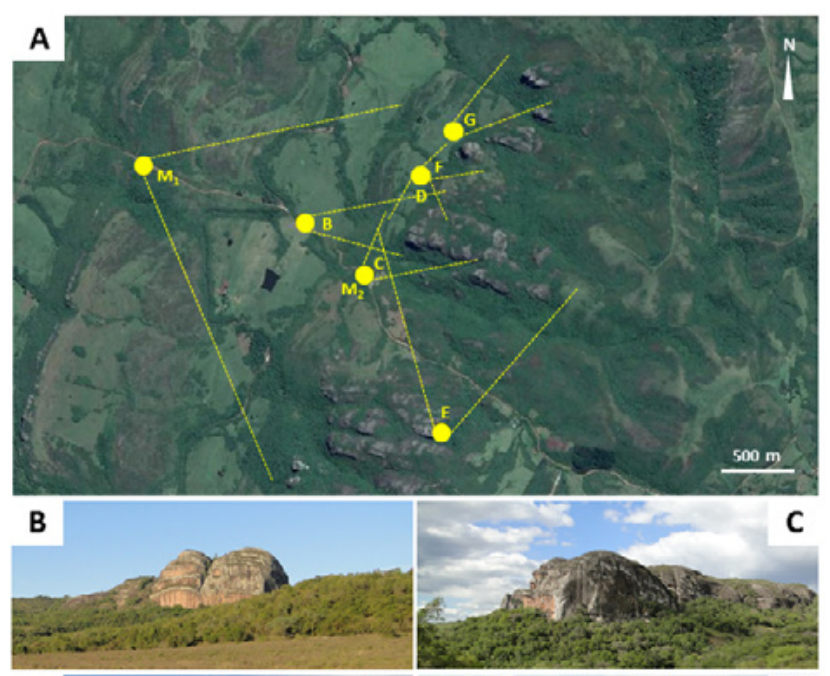

D
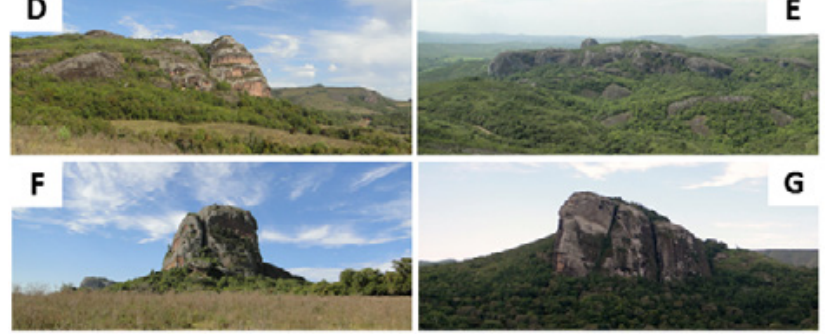

Figura 4 - Cenas e visadas da área da Serra do Segredo: (A) pontos de visada (círculos amarelos) com seu respectivo alcance visual (linhas que divergem a partir de cada ponto) e indicação da cena resultante, sobre imagem (meramente ilustrativa) do GoogleEarth $\AA$; (B, C, D, E) cenas da geoforma Pedra do Segredo, obtidas de diferentes pontos; (F) cena da Pedra da Abelha; (G) cena da geoforma Pedra do Índio..

Fonte: Organização do autor

Como indicações de gestão, sugerem-se aqui como possíveis pontos ideais para a implantação de miradores: (1) o local de coordenadas 30o31'49'"S e 53o34'26"W, na estrada de acesso à Pedra do Segredo, aproximadamente $1,9 \mathrm{~km}$ a oeste do acesso ao geomonumento; e (2) a clareira situada imediatamente a oeste da área de churrasqueiras do próprio terreno da sede do parque municipal que dá acesso ao local, exatamente nas coordenadas 30o32'13'S e 53o33'27,5’W, de fácil acesso. Para ambos 
os locais, a incidência do sol é importante e, por isso, em futuros roteiros (geo)turísticos, a visitação a esses locais deve ser programada para o final do turno da tarde.

Nos domínios das Pedras das Guaritas (Fig. 5A), na porção sul do município, junto ao rio Camaquã, foram analisadas três cenas: duas cenas de geoformas isoladas junto ao terreno da Associação de Moradores das Guaritas (Fig. 5B, 5C) e a cena já citada como melhor avaliada de todo o estudo, constante da Fig. 2A, obtida das margens da RS-625. Enquanto as cenas que retratam cerros isolados receberam notas médias finais de 7,96 a 8,74, a cena onde as geoformas se combinam para formar um conjunto harmônico de morfologia irregular obteve 9,36, demonstrando que a prioridade de gestão deve contemplar a promoção e valorização do local já citado, na RS625 , bem como de outras visadas integradoras.

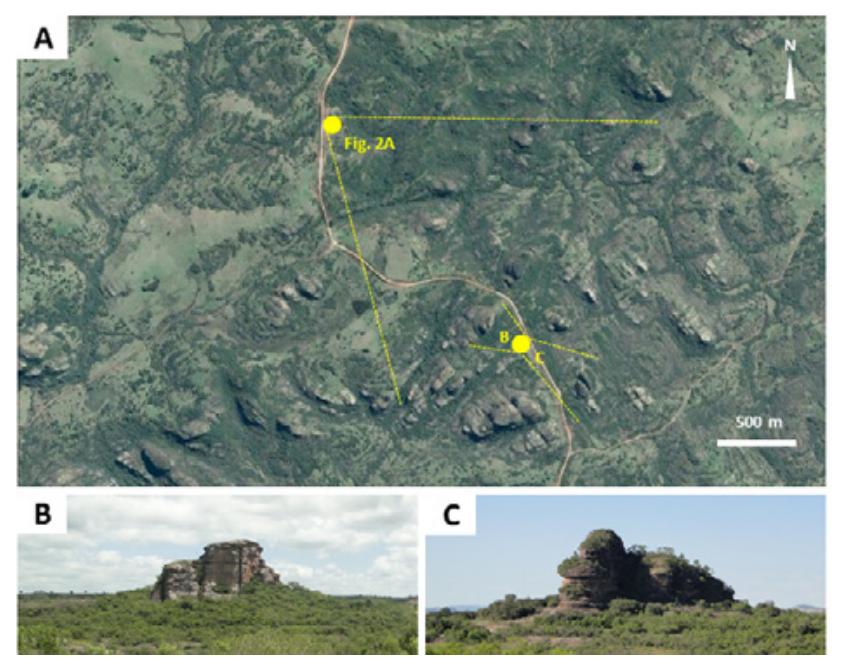

Figura 5 - Cenas e visadas da área das Pedras das Guaritas: (A) pontos de visada e alcance visual, com indicação da cena resultante, incluindo aquela ilustrada na Fig. 2A, composta por várias geoformas agrupadas; $(\mathrm{B}, \mathrm{C})$ cenas de geoformas isoladas na mesma área. Fonte: Organização do autor

\subsection{Cerros de rochas plutônicas e vulcânicas ácidas}

Quatro elevações de rochas ígneas ácidas, resistentes ao intemperismo químico e por isso providas de potencial destaque na paisagem, foram analisadas no âmbito do presente trabalho.

O Cerro do Perau, situado próximo à zona urbana (Fig. 6A) e formado por granitos leucocráticos (UFRGS, 1998; BORBA et al., 2013), é muito interessante para ilustrar a origem do nome do município, que em guarani significa "clareira na mata", pois sobre aqueles granitos não é possível a formação de camadas de solo espesso nem de vegetação de maior porte, configurando "clareiras". Essa elevação foi avaliada por meio de duas cenas obtidas de diferentes pontos de observação. A primeira cena (Fig. 6B), tomada de sul para norte a partir da estrada vicinal que leva da zona urbana ao Cerro do Reginaldo, no ponto de coordenadas 30o27'40"S e 53o27'22'W, distante cerca de $6,4 \mathrm{~km}$ da rodovia BR-392, recebeu nota final de 6,78, com desvio-padrão de 1,87 .

A segunda cena, já ilustrada na figura 2C, tomada de leste para oeste, a partir de uma estrada vicinal que se origina daquela anterior, após uma inflexão para norte, a $2 \mathrm{~km}$ do ponto anterior, nas coordenadas 30o26'35"s e 53o27'20'W, recebeu nota final 5,80, com desvio de 2,03. Na cena melhor avaliada, além de haver exposição de rocha mais evidente, a forma do cerro resulta mais irregular, e a presença do elemento antrópico (a pequena casa à direita na fotografia) parece auxiliar no resultado final da avaliação.

Assim, sugere-se, para a interpretação geopatrimonial e paisagística do Cerro do Perau, uma intervenção (um mirador, por exemplo) no ponto ilustrado na figura $6 \mathrm{~B}$, pois envolveria menor deslocamento em estrada vicinal de chão batido e teria uma apreciação potencialmente maior pelos visitantes.

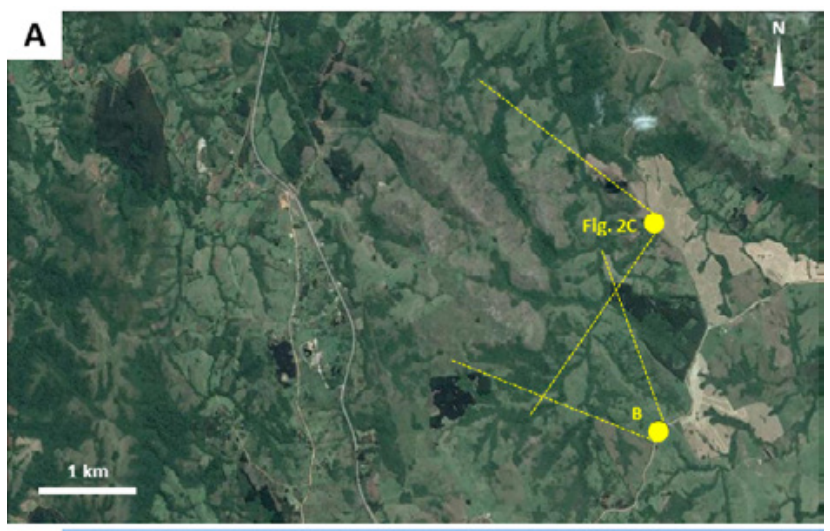

B

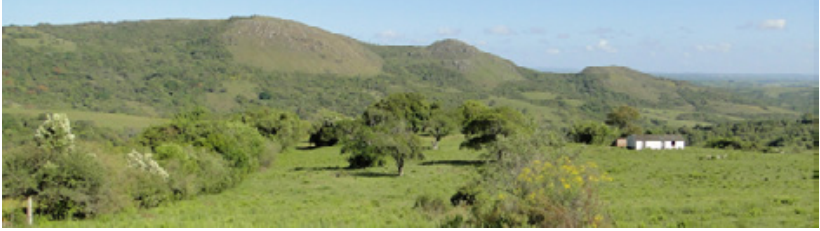

Figura 6 - Cenas e visadas do geomonumento do Cerro do Perau: (A) posição das duas visadas de observação avaliadas, com suas amplitudes visuais, ilustradas na Fig. $2 \mathrm{C}$ e em B; (B) a cena melhor avaliada para o Cerro do Perau, de sul para norte.

Fonte: Organização do autor

Elevações resultantes da maior resistência de rochas vulcânicas ácidas (riolitos e ignimbritos) ao intem- 
perismo também se destacam em Caçapava do Sul, especialmente na Serra de Santa Bárbara, na região oeste do município (Fig. 7A).

Três dessas elevações foram avaliadas ao longo deste projeto. Os cerros dos Machados (Fig. 7B) e dos Nascimentos (já ilustrado na Fig. 2D), visualizados a partir da estrada vicinal que liga o Cerrito do Ouro ao Passo da Promessa, obtiveram respectivamente as notas finais 5,82 e 5,23, entre as mais baixas do acervo avaliado. Já o Cerro do Bugio (Fig. 7C), de substrato geológico semelhante (Formação Acampamento Velho), visualizado a partir de um ponto na estrada do Passo do Megatério, nas coordenadas 30o28'14'S e 53o37'18', obteve uma nota substancialmente mais alta para o destaque na paisagem, de 8,49, com desvio-padrão de 1,48. Isso se deve, sobretudo, a três fatores: (a) a altura do cerro, de cerca de 260 metros de desnível (com seu topo a 403 metros de altitude); (b) seu relativo isolamento, em meio às planícies dos arroios Pessegueiro e Santa Bárbara; e (c) a presença de rocha exposta em sua face sudoeste.

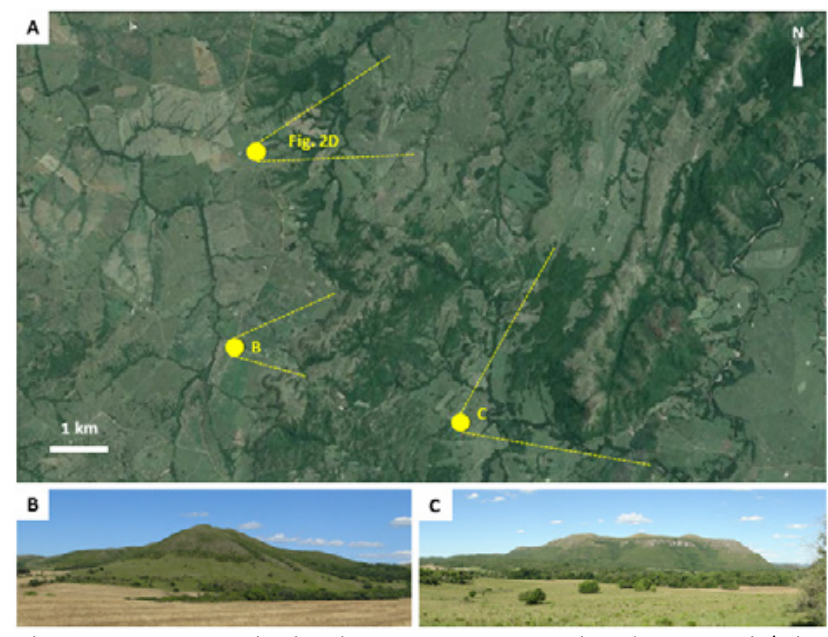

Figura 7 - Cenas e visadas de geomonumentos de substrato vulcânico na região oeste de Caçapava do Sul: (A) posição das três visadas onde foram obtidas as cenas utilizadas nesta pesquisa, sobre imagem (me-

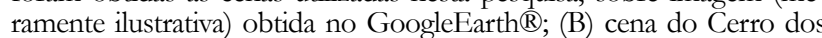
Machados; (C) cena do Cerro do Bugio, que obteve a melhor nota entre os cerros vulcânicos do município.

Fonte: Organização do autor

\subsection{Cerro da Angélica}

O Cerro da Angélica, relativamente isolado, com mais de 200 metros de altura em relação ao entorno (com seu topo a 335 metros de altitude) e situado próximo ao entroncamento entre as rodovias asfaltadas BR-392 e BR-153 (Fig. 8A), é certamente uma das elevações de maior visibilidade de todo o município de Caçapava do
Sul. Suas características fazem deste um ponto ideal para a prática de diferentes modalidades de voo livre, especialmente o paraglider. Formado por rochas sedimentares e vulcânicas do Grupo Bom Jardim, o Cerro da Angélica foi avaliado a partir de três pontos de visada diferentes, para estabelecer uma prioridade na implantação de um mirador.
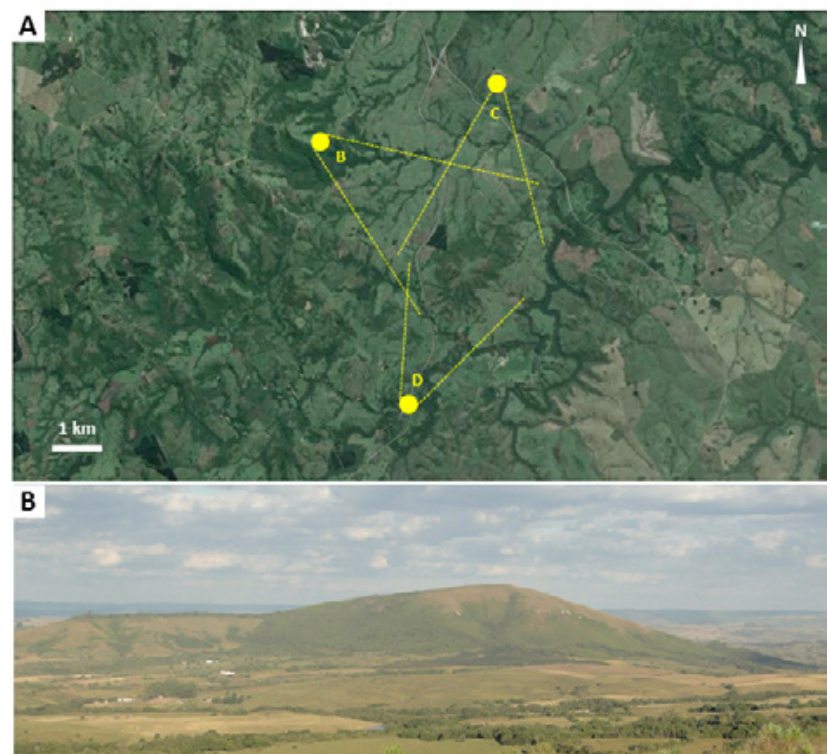

C

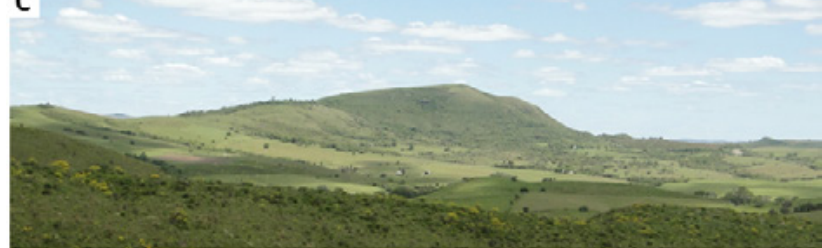

D

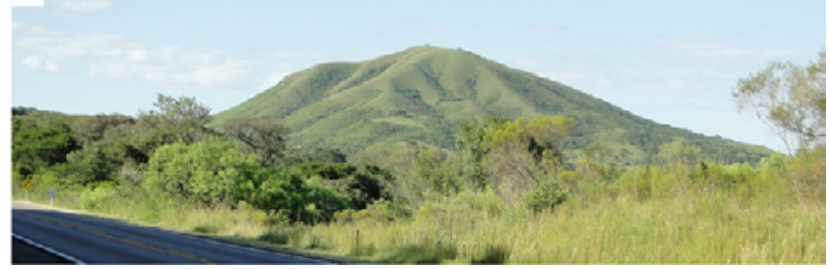

Figura 8 - Cenas e visadas do Cerro da Angélica, um dos geomonumentos de maior visibilidade de Caçapava do Sul: (A) posição dos três pontos de onde foram obtidas as visadas avaliadas neste trabalho, sobre imagem do GoogleEarth ${ }^{\circledR}$; (B, C, D) as três cenas cujo destaque na paisagem foi avaliado no presente trabalho, sendo que a cena ilustrada em D foi aquela mais bem valorada, com 7,88 de média final.

Fonte: Organização do autor

O primeiro ponto, de coordenadas 30o35'49's e 53o24'55'W, fica a 300 metros de altitude, e a 3,5 km de distância em linha reta em relação ao cerro, em uma estrada vicinal que liga a BR-153 ao distrito de Santo Antônio. A cena resultante (Fig. 8B) retrata o cerro frontalmente e a partir do alto, tornando-o quase uma crista de $1,5 \mathrm{~km}$ de extensão, perpendicular à direção de obtenção da fo- 
tografia, de noroeste para sudeste. A nota final obtida por esta cena foi de 6,61 (desvio de 2,25).

O segundo ponto de visada, de coordenadas 30o35'13"S e 53o22'55"W, localiza-se em uma pedreira desativada, onde eram extraídos argilitos utilizados em cerâmicas tipo "porcelanato", em um terreno muito próximo à BR-392, a leste do entroncamento com a BR-153. Obtida de norte para sul desde uma altitude de 162 metros sobre o nível do mar, e também a 3,5 km de distância do topo do Cerro da Angélica, a fotografia (Fig. 8C) recebeu nota final de 5,96 (desvio de 1,98), sendo o local menos favorável (apenas do ponto de vista do destaque na paisagem) para a implantação de um mirador para observação daquela elevação.

O terceiro potencial mirador, localizado às margens da BR-153, no ponto de coordenadas 30o38'27'S e 53o23'55'W, está a uma altitude de 120 metros sobre o nível do mar e a 2,6 km do Cerro da Angélica, e portanto permite uma visualização daquela elevação de sul para norte e do vale em direção ao topo (Fig. 8D). Por ser o flanco mais íngreme do cerro, a altura aparente e, portanto, a imponência do Cerro da Angélica, são maiores nessa visada, que recebeu a nota final mais alta, de 7,88 (desvio de 1,88). Observado desse local, especialmente no fim da tarde, no verão, o Cerro da Angélica assemelha-se a um tapete verde puxado para o alto, como efeito de seus sucessivos talvegues e interflúvios iluminados desde oeste. Esta seria a localização ideal para um mirador pois, além de estar na rodovia asfaltada que leva à cidade de Bagé, permite uma apreciação estética maior desse geomonumento.

\section{CONCLUSÕES}

O levantamento da percepção de estudantes em nível de pós-graduação sobre os critérios estéticos, especificamente o "destaque na paisagem", de diferentes geomonumentos no município de Caçapava do Sul, ao longo de quatro anos de observações, permitiu inferir alguns detalhes sobre a avaliação e a gestão de potenciais miradores. As cenas melhor avaliadas para o município de Caçapava do Sul representam geomonumentos altos em relação ao seu entorno, com formas irregulares, e que se combinam para formar conjuntos harmônicos e complexos. A presença de uma grande diversidade de cores é importante na construção do destaque na paisagem, assim como o ângulo de incidência da luz solar, que re- alça essa diversidade cromática. A presença de vegetação nativa preservada, assim como a presença de elementos antrópicos em harmonia com o ambiente passa uma sensação de tranquilidade e segurança, que é valorizada pelo observador.

Merece atenção o fato de que a nota de destaque na paisagem de um geomonumento nunca é única, especialmente em elevações de grande visibilidade, pois revela-se muito dependente do ponto a partir do qual o objeto é visualizado. Esse destaque é função tanto da declividade da vertente observada quanto da relação entre a altura do ponto de observação e do cerro. Isso fica muito claro ao se observarem as avaliações das três diferentes cenas do Cerro da Angélica, que resultaram em valores discrepantes. Longe de ser uma limitação ao uso dos critérios visibilidade e destaque na paisagem, essas diferenças podem ser utilizadas por gestores públicos e privados na seleção de locais prioritários para a implantação de miradores e de outros mecanismos de interpretação ambiental, geopatrimonial e paisagística.

Especificamente com relação ao caso de Caçapava do Sul, e ao conjunto de cenas e geossítios aqui avaliados, sugere-se como prioridades para a implantação de meios de interpretação geopatrimonial, dentro de uma estratégia municipal ou regional de (geo)turismo, os pontos de visualização das Pedras das Guaritas e do conjunto do Cerro da Cruz, ambos na rodovia estadual RS-625. Paralelamente, merece também atenção a possibilidade de implantação desses mecanismos em um dos pontos de visualização da paisagem da Serra do Segredo, de oeste para leste, para apreciação no final da tarde. Mais estudos relacionados ao potencial de uso, ao número de turistas, moradores ou motoristas eventualmente atingidos por tais iniciativas devem ser realizados, visando à adequada seleção do meio de interpretação a ser implementado.

\section{REFERÊNCIAS BIBLIOGRÁFICAS}

ARRIAZA, Manuel, CAÑAS-ORTEGA, Juan Francisco, CAÑAS-MADUEÑO, Juan Antonio, RUIZ-AVILES, Pedro. "Assessing the visual quality of rural landscapes". Landscape and Urban Planning, v. 69, n. 1, p. 115-125, jul 2004.

BORBA, André Weissheimer de, SOUZA, Luiz Fernando de, MIZUSAKI, Ana Maria Pimentel, ALMEIDA, Delia del Pilar Montecinos de, STUMPF, Paola Prates. "Inventá- 
rio e avaliação quantitativa de geossítios: exemplo de aplicação ao patrimônio geológico do município de Caçapava do Sul (RS, Brasil)". Pesquisas em Geociências, v. 40, n. 3, p. $275-294,2013$.

BORBA, André Weissheimer de, SILVA, Elisângela Lopes da, SOUZA, Luiz Paulo Martins, SOUZA, Luiz Fernando de, MARQUES, Rosane Vera. "Relação entre a geodiversidade intrínseca e a estruturação de habitat na escala do geossítio: exemplos na Serra do Segredo e nas Pedras das Guaritas (Caçapava do Sul, RS, Brasil)". Pesquisas em Geociências, v. 43, n. 2, p. 183-202, 2016.

BRILHA, José Bernardo Rodrigues. Património geológico e geoconservação. Viseu: Palimage Editores, 190p., 2005.

BRILHA, José Bernardo Rodrigues. "Inventory and quantitative assessment of geosites and geodiversity sites: a review”. Geoheritage, v. 8, n. 2, p. 119-134, 2016.

FASSOULAS, Charalambos, MOURIKI, Dimitra, DIMITRIOU-NIKOLAKIS, Panagiotis, ILIOPOULOS, George. "Quantitative assessment of geotopes as an effective tool for geoheritage management". Geoheritage, v. 4, n. 3, p. 177-193, 2012.

FUERTES-GUTIÉRREZ, Inés, FERNÁNDEZ-MARTÍNEZ, Esperanza. "Geosites inventory in the Leon Province (Northwestern Spain): a tool to introduce geoheritage into regional environmental management". Geoheritage, v. 2, p. $57-75,2010$.

GRAY Murray. Geodiversity: valuing and conserving abiotic nature. Chichester: Wiley, 448p., 2004.

HENRIQUES, Maria Helena, PENA-DOS-REIS, Rui, BRILHA, José Bernardo Rodrigues, MOTA, Teresa. "Geoconservation as an emerging geoscience". Geoheritage, v. 3, n. 2, p. 117-128, 2011.

LIMA, Flávia Fernanda de, BRILHA José Bernardo Rodrigues, SALAMUNI Eduardo. "Inventorying geological heritage in large territories: a methodological proposal applied to Brazil’. Geoheritage, v. 2, p. 91-99, 2010.

MARTÍNEZ-VEJA, Javier, MARTIN-ISABEL María Pilar, ROMERO-CALCERRADA, Raúl. "Valoración del paisaje en la zona de especial protección de aves carrizales y sotos de Aranjuez (Comunidad de Madrid)". GeoFocus
(Artículos), v. 3, p. 1-21, 2003.

PENA-DOS-REIS, Rui, HENRIQUES, Maria Helena. "Approaching an integrated qualification and evaluation system for geological heritage”. Geoheritage, v. 1, p. 1-10, 2009.

PEREIRA, Ricardo Galeno Fraga de Araújo. Geoconservação e Desenvolvimento Sustentável na Chapada Diamantina (Bahia - Brasil). 2010. Tese de Doutorado, Escola de Ciências, Universidade do Minho, Braga, 318p.

RIO GRANDE DO SUL 2015. Lei Ordinária Estadual 14.708, de 15 de julho de 2015 - Declara o Município de Caçapava do Sul “Capital Gaúcha da Geodiversidade”. Disponível em http://www.al.rs.gov.br/filerepository/repLegis/arquivos/LEI\%2014.708.pdf, acesso em 19/9/2016.

SOULÉ Michael E. Mente na biosfera; mente da biosfera. In: WILSON, Edward O. (Ed.) Biodiversidade. Rio de Janeiro: Nova Fronteira, p. 593-598, 1997.

UFRGS. Universidade Federal do Rio Grande do Sul. "Mapeamento geológico 1:25.000 de parte das folhas Durasnal, Passo do Salsinho, Caçapava do Sul e Arroio Santa Bárbara". Trabalho de Graduação, Universidade Federal do Rio Grande do Sul, inédito, 1998.

ZUBE Ervin H., SELL James L., TAYLOR, Jonathan G. "Landscape Perception: Research, Application and Theory”. Landscape Planning, v. 9, p. 1-33, 1982.

ZUBE Ervin H., SIMCOX David E., LAW Charles S. "Perceptual landscape simulations: history and prospect". Landscape Journal, v. 6, p. 62 - 80, 1987.

\section{Correspondência do autor:}

André W. de Borba

e-mail: awborba.geo@gmail.com

Artigo recebido em: 02/11/2016

Revisado pelo autor em: 18/01/2017

Aceito para publicação em: 22/01/2017 